\title{
Use of Monopolar Cauterization by Cystoscopy for Ectopic Intramural Ureter Correction in a Bitch
}

\author{
Ariele Aparecida Ferreira', Neíse Nathalie Guariza Tortato ${ }^{1}$, William Timboni Teixeira', \\ Vinicius Gonzalez Peres Albernaz², Roberta Carareto', Tilde Rodrigues Froes', \\ Jorge Luiz Costa Castro ${ }^{3} \&$ Peterson Triches Dornbusch ${ }^{1}$
}

\begin{abstract}
Background: The ectopic ureter (EU) is considered a congenital anomaly in which the ureteral aperture opens in a position other than the bladder neck. The diagnosis involves the use of different methods or combination of image exams, including excretory urography, pneumocystography, ultrasonography, cystoscopy and computed tomography. The technics for surgical repair should be considered evaluating the number and functionality of the EU, the location of the ureteral opening, functional condition of ipsilateral kidney and the presence of other abnormalities. The case reports aims to show the surgical repair of an intramural EU in an English Bulldog bitch by cystoscopy-guided monopolar cautery.

Case: A 1-year-old English Bulldog bitch received medical care due to a history of urinary incontinence since a few months of life. The animal had laboratory abnormalities compatible with lower urinary tract infection, followed by a profound growth of Klebsiella sp in urine culture, and received antibiotic treatment for 21 days based on antibiogram results. Due to a suspect EU, a urinary tract tomography was performed and indicated a congenital kidney malformation (renal dysplasia), enlargement and distal insertion of the left ureter (in comparison with the contralateral one), rising suspiciously of its intramural progression. We choose to proceed to cystoscopy examination, in which both right and left ureteral ostium could be seen in the urethral region. A guide of a pigtail catheter was inserted through both ureteral ostia in order to orient the ureteral incision. The monopolar cautery was inserted in cystoscopy working channel to section the mucosa of EU channel on urethra region, separating the lumen of EU from the urethra and extending the incision cranially inside the urinary bladder lumen. After a complete section of the ectopic tissue, a pigtail urinary catheter was correctly placed in both ureters. After bilateral repair of EU, the bitch showed a significative decrease of urinary incontinence, although full resolution could not be obtained.

Discussion: Studies showing the treatment of EU using the ablation of the tissue separating the ureteral and urethral or bladder lumen using cystoscopy-guided laser showed lower post-operative pain and hospitalization time, besides being a minimally invasive technique in comparison with traditional surgery. The limiting factor is the specialized equipment required for the procedure. In our surgical routine, there is a cystoscope, however, we do not own a diode laser or radiofrequency equipment. The adaptation of a monopolar cautery with the objective of correct an intramural EU proved to be feasible in practice since we achieved satisfactory recovery of the patient, similar than what is seen with lasers. Even after surgical repair of both EU, the patient sustained urinary incontinence, although lesser than before surgery. The remaining of the clinical sign, in this case, is compatible with the low rate of postoperative urinary continence in bitches, irrespective of the surgical technique, varying between $25 \%$ and $58 \%$ with or without medical treatment. To our knowledge, there was no published report on the use of monopolar cautery to treat EU. The monopolar cautery can be used as a less invasive and alternative technique to traditional surgery in the treatment of intramural EU through cystoscopy in bitches.
\end{abstract}

Keywords: urinary incontinence, ureteral ectopia, pigtail catheter. 


\section{INTRODUCTION}

The ectopic ureter (EU) is a congenital anomaly in which the ureteral ostium opens somewhere different than the bladder neck, such as in female the uterine cervix, urethra or vagina [1-4,7,9]. EU can be classified as intramural and extramural based of ureter way until its terminal aperture. When intramural, the EU goes through the mucosal and submucosal layer of the bladder to debouch in the urethral or vaginal area [1-4,9].

The EU is often associated with other urogenital anomalies, such as renal aplasia, renal hypoplasia, ureterocele, hydronephrosis, hydroureter, anomalies of the ureterovesical junction, pelvic bladder, and urethral sphincter mechanism incompetence [2-4,9]. The diagnosis of EU evolves the single or combined use of several image exams, including excretory urography, pneumocystography, ultrasonography, cystoscopy, computed tomography (CT) and magnetic resonance image [4].

The choice of a surgical technique should be based on the number and functionality of the EU, the location of ureteral aperture, functional condition of ipsilateral kidney and the presence of other malformations [9]. The aim of this case is to report the surgical repair of an intramural EU in an English Bulldog bitch using a cystoscopy-guided monopolar cautery.

\section{CASE}

A 1-year-old, English Bulldog bitch was treated on the Veterinary Hospital of the Federal University of Paraná (HV - UFPR) for juvenile urinary incontinence, worsening in the last months. In regard to physical examination, all parameters were within normal ranges, but the patient had vulvar fold dermatitis. Complete blood count and serum biochemistry resulted in no abnormalities. The urine was light yellow with a density of 1.022, proteinuria $(+1)$, leukocyturia (6-9/field), bacteriuria (+1) and hematuria (1-2/field). There was a profound growth of Klebsiella sp. on urine culture. The patient was treated with Amoxicillin and potassium clavulanate $\left(\text { Clavulin }^{\circledR}\right)^{1}[22 \mathrm{mg} / \mathrm{kg}$, BID for 21 days] based on test of antimicrobial susceptibility.

The abdominal ultrasound resulted in an enlarged left kidney with preserved form but irregular edges, a discreetly thickened cortex, preserved echogenicity, diminished corticomedullary differentiation and dilated renal pelvis $(0.24 \mathrm{~cm})$, but the left ureter could not be visualized. The right kidney was decreased in size, with loss of its form, irregular edges, the heterogeneous aspect with hyperechoic spots, without a corticomedullary differentiation, dilated renal pelvis $(0.58 \mathrm{~cm})$ and an enlarged right ureter $(0.37 \mathrm{~cm})$ until its insertion on bladder trigone.

Due to the suspect of EU, a CT urography was performed on transverse sections ( 3 and $2 \mathrm{~mm}$ ), sagittal and dorsal reconstructions using soft tissues window. Scanning protocol used was $100 \mathrm{kV}$ and 100 $\mathrm{KmAs}, 2 \mathrm{~mm}$ slice thickness. Contrast was provided by iopromida (Ultravist $\left.{ }^{\circledR} 300\right)^{2}[623 \mathrm{mg} / \mathrm{mL}$ iv; 800 $\mathrm{mg} / \mathrm{kg}$ ]. Postcontrast image acquisition was initiated immediately after end of bolus contrast administration and second and third delay postcontrast scans were also acquired 5 and $10 \mathrm{~min}$ after the initiation of contrast injection. All post-contrast scanning used the same parameters of the non-contrast study. The images confirmed the findings of the ultrasound, indicating a congenital malformation of both kidneys (renal dysplasia), but in the right kidney, the atrophy/hypoplasia was more important. The path of the ureters could be followed to the caudal retroperitoneal/pelvic region, where the diameter of the left ureter was larger than the contralateral. The right ureter had a deviation in its path due to the presence of fecal material on colon; However, mild focal distension of the ureter's lumen could be seen near the ascending colon, bordering it dorsolaterally and following ventrally where it was inserted on urinary bladder. The left ureter insertion seemed distal than the contralateral, rising suspiciously of its intramural progression distal to vesical colon neck. The retention of contrast on the urethral wall was an indirect indicator of EU and/or indicative of a sphincter incompetence (Figure 1).

The patient underwent a cystoscopy in which the anesthetic induction was performed with propofol $\left(\text { Propovan }^{\circledR}\right)^{3}$ [4 mg/kg IV], maintained with inhalatory isoflurane (Isoforine $\left.{ }^{\circledR}\right)^{3}$ per an 8.0 tracheal tube in a semi-closed circuit, spontaneous ventilation, air flow of $2.0 \mathrm{~L} / \mathrm{min}$, and $100 \% \mathrm{FiO} 2$. Analgesia was obtained through constant-rate infusion of Suflk [5 $\mathrm{mL} / \mathrm{kg} / \mathrm{h})]$, composed of sufentanil citrate $\left(\text { Fastfen }^{\circledR}\right)^{3}$ [1 $\mathrm{mcg} / \mathrm{kg} / \mathrm{h}$ ]; lidocaine $2 \%$ without vasoconstrictor (Hypocaína $\left.^{\circledR}\right)^{4}[0.5 \mathrm{mg} / \mathrm{kg} / \mathrm{h}]$; ketamine (Quetamina ${ }^{\circledR}$ injetável $)^{5}[0.6 \mathrm{mg} / \mathrm{kg} / \mathrm{h}]$; diluted in isotonic sodium chloride $0.9 \%$ solution (Linhamax) ${ }^{6}$. There was no anesthetic complication during the procedure. 


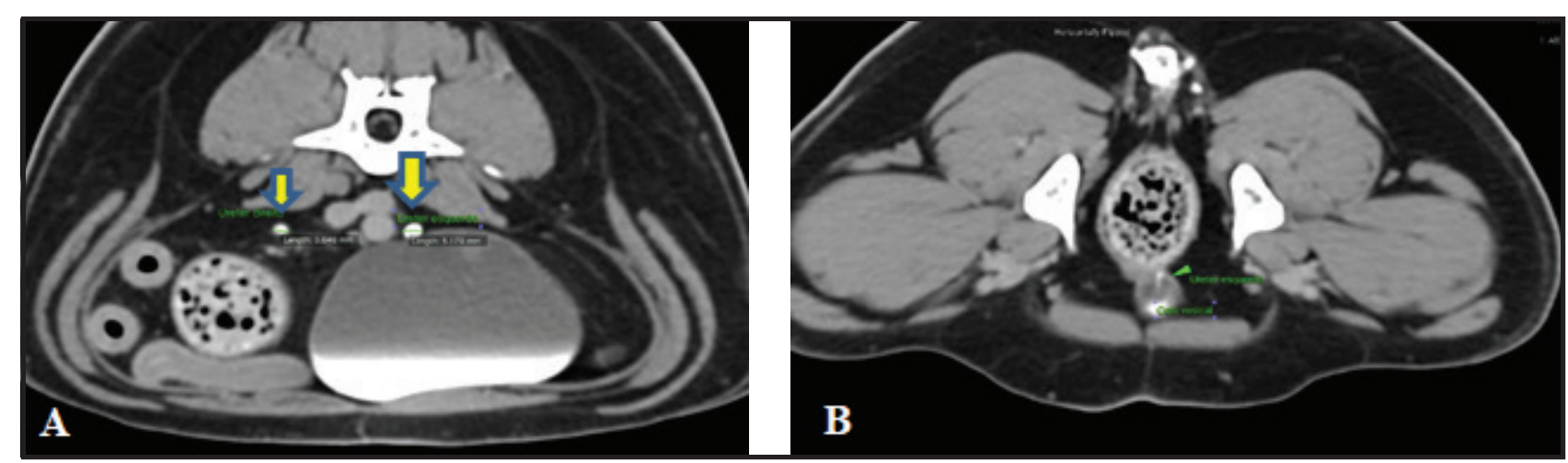

Figure 1. Transversal image of the computed tomography scan from an English bulldog bitch (A \& B). The images were obtained in the late phase (3 min) after intravenous injection of contrast media. A- Right (minor arrow), left ureter (major arrow) and the urinary bladder filled with contrast. The right ureter deviates due to the colon full of feces. B- The presence of contrast in the bladder neck. The urethral wall is also highlighted, by contrast, an indirect sign of EU associated or not to urethral sphincter incompetence.



Figure 2. Cystoscopy image of the ectopic ureter. A- The aperture of the right intramural ectopic ureter on the region caudal to the urethral sphincter. B-Aperture of the left intramural ectopic ureter before surgical correction.

The patient was positioned in dorsal recumbency and the vagina and urethra were examined using a 5-mm rigid cystoscopy with a passive flow of Ringer's lactate solution (Isobag $\left.{ }^{\circledR}\right)^{7}$. During the cystoscopy examination the presence of both ureteral ostia were found caudal to the urethral sphincter. Also, the ureter was inserted in the bladder neck, but following an intramural path until caudal to the urethral sphincter. Therefore, the diagnosis was bilateral intramural EU (Figure 2).

A hydrophilic guide of pigtail catheter was placed in the ureter to orient the incision, and then the monopolar cautery was inserted in cystoscope working channel to section the mucosa and extending the incision cranially to the bladder separating the lumen of EU from the urethra. After that, the pigtail catheter was correctly positioned on both ureter with one extremity on the renal pelvis and the other on the urinary bladder (Figure 3).

On the post-operative period, the patient received carprofen $\left(\operatorname{Rimadyl}{ }^{\circledR}\right)^{8}[2.2 \mathrm{mg} / \mathrm{kg}$ BID for 3 days], tramadol hydrochloride $\left(\operatorname{Tramal}^{\circledR}\right)^{9}[4 \mathrm{mg} / \mathrm{kg}$ TID for 5 days] and maintained the use of amoxicillin with potassium clavulanate $\left(\text { Clavulin }^{\circledR}\right)^{1}$ [for 11 days], when the pigtail catheter was removed by cystoscopy. At that time the distal ureters were open, well healed, without signs of edema or tissue debris, and its opening was cranial to the urethral sphincter (Figure 3).

After the procedure, the patient had no urinary incontinence for about a month, returning to clinical signs approximately 4 weeks after removal of the pigtail catheter. A new urine culture resulted in the growth of Escherichia coli, leading to the return of antimicrobial therapy with amoxicillin with potassium 


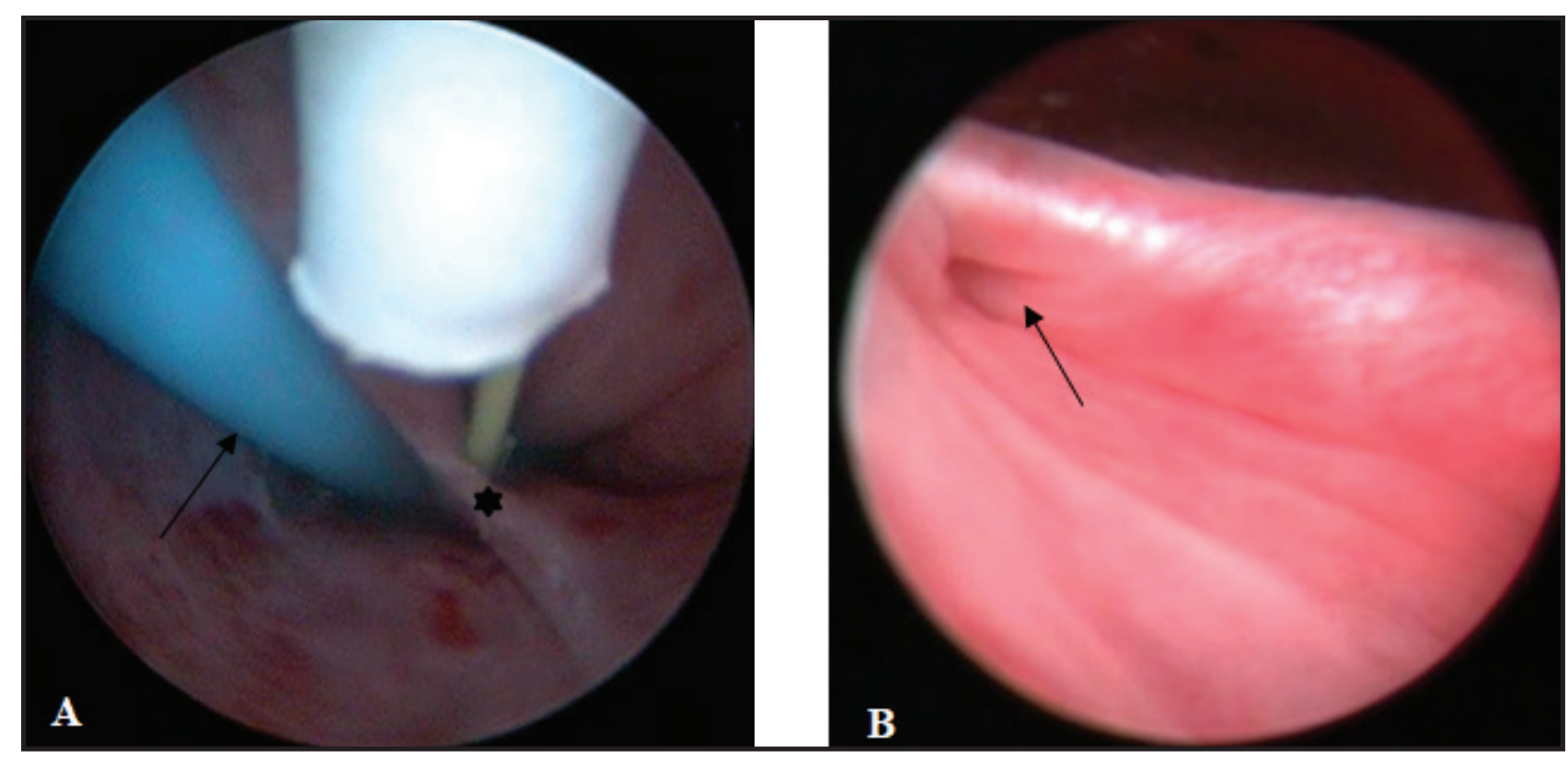

Figure 3. Cystoscopy images of the surgical procedure and postoperative evaluation. A- Shows the guide of a pigtail catheter (arrow), monopolar cautery and ectopic ureteral tissue $(*)$. The pigtail catheter was used to guide the incision of the ectopic ureteral tissue. B- Aperture of the right ureter after surgical correction of ectopic ureter using monopolar cautery.

clavulanate $\left(\text { Clavulin }^{\circledR}\right)^{1}$ [22 $\mathrm{mg} / \mathrm{kg}$ BID for 21 days] in accordance with another test of antimicrobial susceptibility.

The animal had a significant decrease on urinary incontinence after surgical correction of the EU, however, mild incontinence persisted without signs of urinary infection two months after the surgery.

\section{DISCUSSION}

The patient of this case report had continuous clinical signs of urinary incontinence since 4-month-old, been the definitive diagnosis obtained approximately at 1-year-old, history and age compatible with what was described in the literature for a congenital disease $[1,2,4,9]$.

Some breeds are predisposed to EU, such as Siberian Husky, Golden Retriever, Labrador Retriever, Terra Nova, Poodle, Fox Terrier and Skye Terrier [14]. However, the English Bulldog is not described as a predisposed breed, but the incidence of EU in this breed has been increasing as the prevalence of English Bulldog also raised in the canine population [6].

There is greater involvement in female, as occurred in the patient of this case report $[3,4,9]$, however, the actual prevalence in male dogs is probably underestimated [2,9]. The infection of the urinary tract at the moment of the diagnosis is also a common finding in dogs with EU, as seen in this patient [6].
The ultrasonography allowed the morphological evaluation of the kidney, indicating a condition of renal dysplasia and right kidney hypoplasia [11]. The presence of right renal pelvis and ureter indicated a probable anomaly of the ureter, even though its insertion could be seen in the bladder neck. The evidence of dilated ureter is an abnormal finding of the ultrasound, with the main differential diagnosis being a partial obstruction [5], in this case probably associated with the ureteral intramural deviation (right side).

The CT is one of the most sensitive methods to diagnose an EU [10]. In this case, the CT was not completely elucidative for a definitive diagnosis of the intramural EU of the right side despite the indirect findings of urethral opacification and dilatation but found abnormalities associated to the ectopia and its differentials diagnosis. The difficulty to obtain an adequate prepare and to partially cleansing of the descending colon by an enema may have impaired the evaluation of the ureteral deviation, even though it is a technique that provides cross-sections of the tissues. The presence of contrast opacification in the urethra (anterograde) also indirectly indicated the EU, associated or not to the sphincter insufficiency. The CT of the urinary tract also confirmed the dysplasia and hypoplasia of the right kidney. Therefore, we believe that the association of cystoscopy was essential to visualize and confirm the diagnosis of bilateral EU [3,4], and was superior to the $\mathrm{CT}$ in this case. 
In the treatment of the EU, the ablation of the tissue separating the ureteral lumen from the urethral lumen or the bladder using cystoscopy-guided laser has the main advantages the reduced pain and hospitalization time on the post-operative period, as well as being a less invasive surgery than traditional surgery [3]. The most important fact that limits the use of cystoscopy-guided ablation is the need for specific equipment [12]. Currently, we use cystoscopy in the surgical routine, however, we do not have a diode or radiofrequency laser equipment. The adaptation of a monopolar cautery with the objective of treat an intramural EU proved to be feasible to the practitioner, since this way we could reach a similar recovery and outcome of the patient than with the use of a laser. There is no current published report of the use of this kind of cautery to treat EU in the literature.

The risks associated with the use of cystoscopy-guided laser ablation is the urethral or vesical rupture resulting in uroretroperitoneum or uroabdomen, bleeding and ureteral recanalization [2,12]. None of these complications was observed in this case, however, as a precaution, it was decided to use the pigtail catheter during the procedure. In addition to these complications, the authors warn upon the possibility of edema due to the use of monopolar cautery, which may lead to stenosis of the distal portion of the ureter. In addition, the pigtail catheter acted as a guide to transect of the ureteral wall during the surgical procedure.

The urodynamic test is indicated in patients with urinary incontinence, as this clinical sign can persist on the post-operative [4]. Some causes to this phenomenon include the remnant distal EU, sphincter incompetence, recanalization of the distal ureteral segment, hypoplasia of the urinary bladder and vaginal vestibular stenosis, neurogenic abnormalities, hormonal imbalance or inadequate surgery [8].

In this case, the patient had urinary tract infection, which was aggravating the recurrence of urinary incontinence. Despite the correction of both EU and treatment of the urinary tract infection, the patient had persistent signs of incontinence, although discrete than before the surgical procedure. The persistence of this sign is compatible with the literature, where the rated of postoperative urinary continence in bitches remains low regardless of the surgical technique, ranging from $25 \%$ to $58 \%$ with or without concomitant medical treatment [3].

The monopolar cautery can be used through cystoscopy as another option in the treatment of intramural EU in dogs. Its main advantage is a less invasive procedure than traditional surgery.

\section{MANUFACTURERS}

${ }^{1}$ GlaxoSmithKline. Rio de Janeiro, RJ, Brazil.

${ }^{2}$ Bayer. São Paulo, SP, Brazil.

${ }^{3}$ Cristália Produtos Químicos Farmacêuticos. Itapira, SP, Brazil.

${ }^{4}$ Hypofarma. Ribeirão das Neves, MG, Brazil.

${ }^{5}$ Vetnil Ind. e Com. de Produtos Veterinários Ltda. Jacareí, SP, Brazil.

${ }^{6}$ Eurofarma Laboratórios S/A. Ribeirão Preto, SP, Brazil.

${ }^{7}$ Isofarma Industrial Farmacêutica Ltda. Eusébio, CE, Brazil.

${ }^{8}$ Pfizer. Guarulhos, SP, Brazil.

${ }^{9}$ Grünenthal do Brasil. São Paulo, SP, Brazil.

Declaration of interest. The authors report no conflicts of interest. The authors alone are responsible for the content and writing of this paper.

\section{REFERENCES}

1 Balogh O., Degrandi F., Hassig M. \& Reichler I.M. 2015. Validation of screening examinations of the ureteral orifices in dogs: comparison of ultrasonography with dissection. Research in Veterinary Science. 101: 199-205.

2 Berent A.C., Mayhew P.D. \& Porat-Mosenco Y. 2008. Use of cystoscopic-guided laser ablation for treatment of intramural ureteral ectopia in male dogs: four cases (2006-2007). Journal of the American Veterinary Medical Association. 232(7): 1026-1034.

3 Berent A.C., Weisse C., Mayhew P.D., Todd K., Wright M. \& Bagley D. 2012. Evaluation of cystoscopic-guided laser ablation of intramural ectopic ureters in female dogs. Journal of the American Veterinary Medical Association. 240(6): 716-725.

4 Ho L.K., Troy G.C. \& Waldron D.R. 2011. Clinical Outcomes of Surgically Managed Ectopic Ureters in 33 Dogs. American Animal Hospital Association. 47(3): 196-202.

5 Lamb C.R. \& Gregory S.P. 1988. Ultrasonographic findings in $14 \mathrm{dogs}$ with ectopic ureter. Veterinary Radiology and Ultrasound. 39(3): 218-223.

6 MacPhail C.M. 2013. Surgery of the Kidney and Ureter. In: Fossum T.W. (Ed). Small Animal Surgery. Philadelphia: Elsevier, pp.705-734. 
A.A. Ferreira, N.N.G. Tortato, W.T. Teixeira, et. al. 2019. Use of Monopolar Cauterization by Cystoscopy for Ectopic Intramural Ureter Correction in a Bitch. Acta Scientiae Veterinariae. 47(Suppl 1): 426.

7 Newman M. \& Landon B. 2014. Surgical treatment of a duplicated and ectopic ureter in a dog. Journal of Small Animal Practice. 55(9): 475-478.

8 Noel S.M., Claeys S. \& Hamaide A.J. 2017. Surgical management of ectopic ureters in dogs: Clinical outcome and prognostic factors for long-term continence. Veterinary Surgery. 46(5): 631-641.

9 Reichler I.M., Specker C.E., Hubler M., Boos A., Haessig M.H. \& Arnold S. 2012. Ectopic Ureters in Dogs: Clinical Features, Surgical Techniques and Outcome. Veterinary Surgery. 41(4): 515-522.

10 Samii V.F., McLoughlin M.A., Mattoon J.S., Drost W.T., Chew D.J., DiBartola S.P. \& Hoshaw-Woodard S. 2008. Digital fluoroscopic excretory urography, digital fluoroscopic urethrography, helical computed tomography, and cystoscopy in 24 dogs with suspected ureteral ectopia. Journal Veterinary Internal Medicine. 18(3): 271-281.

11 Seiler G.S., Rhodes J., Cianciolo R. \& Casal M.L. 2010. Ultrasonographic findings in cairn terriers with preclinical renal dysplasia. Veterinary Radiology and Ultrasound. 51(4): 453-457.

12 Smith A.L., Radlinsky M.G. \& Rawlings C.A. 2010. Cystoscopic diagnosis and treatment of ectopic ureters in female dogs: 16 cases (2005-2008). Journal of the American Veterinary Medical Association. 237(2): 191-195. 